\title{
Efeitos do processamento da alfafa e da adição de óleo de soja sobre a digestibilidade total da dieta de eqüinos
}

\author{
Alexandre Augusto de Oliveira Gobesso ${ }^{1}$, Celso Luiz Fernandes Lorenzo ${ }^{2}$, Ligia Dias \\ Prezotto $^{3}$, Francisco Palma Rennó ${ }^{1}$
}

\footnotetext{
${ }^{1}$ Departamento de Nutrição e Produção Animal, Faculdade de Medicina Veterinária e Zootecnia, Universidade de São Paulo, Caixa Postal 23, CEP: 13630-970, Pirassununga, SP.

2 Programa de Mestrado em Nutrição e Produção Animal, VNP/FMVZ/USP.

${ }^{3}$ Graduação em Zootecnia - FZEA/USP. Bolsista de Iniciação Científica - CNPq.
}

\begin{abstract}
RESUMO - Avaliou-se o efeito do processamento do feno de alfafa (Medicago sativa L.) e da adição de óleo de soja em dietas sobre a digestibilidade total de matéria seca, matéria orgânica, proteína bruta, extrato etéreo, fibra em detergente neutro e fibra em detergente ácido em eqüinos. Utilizaram-se quatro potros machos, sem raça definida, com aproximadamente 14 meses de idade e 197,25 kg, em delineamento quadrado latino $(4 \times 4)$ e em arranjo fatorial $(2 \times 2)$, composto de duas formas de fenação da alfafa (em cubos ou em ramas) e da adição ou não de óleo de soja em dietas contendo concentrado comercial na forma de péletes. A digestibilidade dos nutrientes foi determinada pelo método de coleta total de fezes durante três dias. A adição de óleo de soja refinado aumentou a digestibilidade total de matéria seca, matéria orgânica, extrato de etéreo e fibra em detergente neutro. A fenação da alfafa em cubos aumentou a digestibilidade total da proteína bruta, fibra em detergente neutro e da fibra em detergente ácido. A adição de óleo de soja nas dietas avaliadas foi um modo prático e seguro de aumentar a densidade calórica sem reduzir a digestibilidade dos macronutrientes orgânicos. O processamento da alfafa na forma de cubos melhorou a digestibilidade total da proteína bruta, fibra em detergente e fibra em detergente ácido da dieta em eqüinos.
\end{abstract}

Palavras-chave: alimentação, cubos de alfafa, óleo de soja, potros

\section{Effects of alfalfa processing and addition of soybean oil on the total diet digestibility of foals}

\begin{abstract}
The effect of alfalfa hay processing (Medicago sativa L.) and the addition of soybean oil in diets on the total dry matter digestibility, organic matter, crude protein, ether extract, neutral detergent fiber and acid detergent in horses was evaluated. Four crossbred male foals with approximately 14 months of age and $197.25 \mathrm{~kg}$ were used and assigned in a $(4 \times 4)$ Latin square design with a factorial arrangement $(2 \times 2)$ composed of two alfalfa haying forms (cubes or branches) and the addition or absence of soybean oil in commercial diets containing concentrated in the form of pellets. The nutrients digestibility was determined by the total feces collection method for three days. The addition of refined soybean oil increased the total digestibility of dry matter, organic matter, ether extract and neutral detergent fiber. The alfalfa processing in the form of cubes increased the total digestibility of crude protein, neutral detergent fiber and acid detergent fiber. The addition of soybean oil in the assessed diets was a practical and safe way to increase the caloric density without reducing the digestibility of organic nutrients. The alfalfa processing in the form of cubes improved the total digestibility of crude protein, detergent fiber and acid detergent fiber in the diet of horses.
\end{abstract}

Key Words: alfalfa cubes, feeding, foals, soybean oil

\section{Introdução}

A proteína e a energia são essenciais para o crescimento Ott (1977), ou seja, as ingestões de níveis adequados de proteína e energia proporcionam ao animal crescimento compatível com seu potencial genético.

A exigência nutricional de energia para eqüinos está relacionada à necessidade de cada categoria e à quantidade, qualidade e digestibilidade da energia (NRC, 1989). A exigência de fibra é importante para manter a estabilidade intestinal e diminuir a susceptibilidade à acidose (MooreColyer et al., 2000).

O conhecimento da composição química e da digestibilidade dos alimentos permite a formulação de rações mais ajustadas às exigências nutricionais dos animais, aumentando seu desempenho. 
A alfafa, uma excelente fonte de proteínas, vitaminas e minerais, fornece substrato para síntese de energia e é considerada na criação de eqüinos uma das melhores opções para produção de feno e alimentação desses animais em todas as idades e fases de produção (NRC, 1989; Crozier et al., 1997).

O fornecimento de forragem em cubos tem sido uma alternativa para alimentar eqüinos em detrimento à forma tradicional, em ramas, principalmente em centros hípicos urbanos. Em virtude do alto valor nutricional, a alfafa em cubos é um alimento que pode fazer parte de programas nutricionais para éguas, animais em crescimento, adultos e, especialmente, cavalos com certos problemas respiratórios, tendo em vista a baixa exposição do alimento a poeira e bolores e a possibilidade de utilização como fonte não exclusiva de volumoso (Coleman, s/d).

Recentemente foram realizados estudos para avaliar a influência da gordura dietética no arraçoamento e desempenho de cavalos atletas, mas pouco se conhece sobre seu efeito na digestibilidade dos nutrientes de dietas de animais em crescimento. A adição de gordura não afetou o desaparecimento in vitro da matéria seca, matéria orgânica e fibra, nutrientes comuns na avaliação de dietas para eqüino (Bush et al., 2001). Na literatura existem relatos de aumento na digestibilidade da fibra em detergente neutro (Hughes et al., 1995; Julen et al., 1995; Scott et al., 1987; Webb et al., 1987) e fibra em detergente neutro (Rich et al., 1981) em dietas com a adição de gordura.

O objetivo neste estudo foi avaliar o efeito do processamento da alfafa (fenação na forma de cubos ou fardos) e da adição de óleo de soja na digestibilidade aparente dos nutrientes de dietas para potros.

\section{Material e Métodos}

O experimento foi conduzido nas dependências do Setor de Equideocultura do Campus Administrativo de Pirassununga (PCAPS). As análises foram realizadas no Laboratório de Bromatologia do Departamento de Nutrição e Produção Animal da Faculdade de Medicina Veterinária e Zootecnia da Universidade de São Paulo (FMVZ-USP), localizado no município de Pirassununga, São Paulo.

Utilizaram-se quatro eqüinos machos, sem raça definida, oriundos de cruzamentos de raças de esporte, com aproximadamente 10 meses de idade e $197,25 \pm 23 \mathrm{~kg}$, pertencentes ao rebanho da Universidade de São Paulo. Os animais foram vermifugados, pulverizados contra ectoparasitos e imunizados contra tétano 30 dias antes do período experimental.

O estudo foi realizado em quadrado latino $4 \times 4$ (quatro animais, quatro tratamentos e quatro períodos), em esquema fatorial $2 \times 2$, constituído de duas formas de fenação da alfafa (em cubos ou em fardos) e da adição ou não de óleo no concentrado comercial peletizado. As dietas (Tabelas 1 e 2) foram formuladas para atender às exigências de potros em crescimento moderado, com peso previsto à idade adulta $450 \mathrm{~kg}$ de peso vivo, segundo o NRC (1989).

Os animais foram alojados em baias individuais com piso de cimento e cama de maravalha retirada na tarde anterior à colheita de fezes .

As dietas (feno + concentrado) foram fornecidas em duas refeições diárias, divididas em partes iguais em horários constantes, às $7 \mathrm{~h}$ e $19 \mathrm{~h}$. O concentrado foi fornecido separado do volumoso e a água, à vontade (Tabela 3).

O experimento foi realizado em quatro períodos de 11 dias: os oito primeiros para adaptação às dietas experimentais

Tabela 1 - Composição dos ingredientes das dietas experimentais (\% da matéria seca)

\begin{tabular}{|c|c|c|c|c|c|c|c|}
\hline Alimento & MS & MO & PB & $\mathrm{EE}$ & FDN & FDA & MM \\
\hline Alfafa em cubos & 89,76 & 79,95 & 20,51 & 1,63 & 39,44 & 32,79 & 9,81 \\
\hline Alfafa em fardo & 89,91 & 80,92 & 16,79 & 1,35 & 51,24 & 39,94 & 8,99 \\
\hline Concentrado comercial & 90,56 & 75,58 & 13,96 & 3,59 & 39,49 & 15,70 & 14,98 \\
\hline Óleo de soja & 99,80 & 99,7 & - & 99,70 & - & - & - \\
\hline
\end{tabular}

Tabela 2 - Composição das dietas experimentais (base matéria \%)

\begin{tabular}{lcccccccc}
\hline Ingrediente & \multicolumn{2}{c}{ Alfafa em cubos } & \multicolumn{2}{c}{ Alfafa em fardo } & \multicolumn{2}{c}{ Concentrado comercial } & \multicolumn{2}{c}{ Óleo de soja } \\
& $(\%)$ & $(\mathrm{kg})$ & $(\%)$ & $(\mathrm{kg})$ & $(\%)$ & $(\mathrm{kg})$ & $(\%)$ & $(\mathrm{kg})$ \\
\hline Cubo & 55,56 & 2,5 & - & - & 44,44 & 2,0 & - \\
Fardo & - & - & 55,56 & 2,5 & 44,44 & 2,0 & - & - \\
Cubo óleo & 51,87 & 2,5 & - & - & 41,49 & 2,0 & 6,64 & 0,32 \\
Fardo óleo & - & - & 51,87 & 2,5 & 41,49 & 2,0 & 6,64 \\
\hline
\end{tabular}


Tabela 3 - Composição bromatológica das dietas experimentais (\% MS)

\begin{tabular}{lcccccc}
\hline Dieta & MO & PB & EE & FDN & FDA & MM \\
\hline Cubo & 87,88 & 17,58 & 2,51 & 39,46 & 25,16 & 12,12 \\
Fardo & 88,34 & 15,53 & 2,35 & 46,00 & 29,12 & 11,66 \\
Cubo óleo & 88,77 & 16,30 & 9,60 & 36,58 & 23,32 & 11,23 \\
Fardo óleo & 89,19 & 14,39 & 9,45 & 42,64 & 27,00 & 10,81 \\
\hline
\end{tabular}

e os três restantes para coleta total de fezes no piso das baias, de acordo com Araújo et. al.(2003). As fezes foram identificadas e do total coletado, após homogeneização, foram retiradas frações de $10 \%$, que foram acondicionadas em sacos plásticos e congeladas para posteriores análises laboratoriais. Amostras dos ingredientes da dieta foram colhidas durante as quatro fases do experimento e armazenadas para posterior análise laboratorial.

As amostras foram descongeladas a temperatura ambiente, homogeneizadas manualmente, pesadas e secas em estufa de ventilação forçada a $65^{\circ} \mathrm{C}$, por 72 horas. Posteriormente, foram trituradas em moinhos com peneira de $1 \mathrm{~mm}^{2}$ para formação de amostras compostas, com base no peso seco, para cada animal e período, que foram moídas e acondicionadas em recipiente de vidro, com tampa de polietileno até a realização das análises para determinação dos teores de matéria seca (MS), matéria orgânica (MO), fibra em detergente neutro (FDN), fibra em detergente ácido (FDA), fibra bruta (FB), proteína bruta $(\mathrm{PB})$, matéria mineral (MM) e extrato etéreo (EE), dos ingredientes da dieta e das fezes, segundo metodologia descrita por Silva (1990) e FDN e FDA, conforme proposto por Van Soest (1982).

As análises estatísticas foram realizadas pelo procedimento GLM (General Linear Model), do programa Statistical Analysis System (SAS, 1985), depois de verificada a normalidade dos resíduos pelo teste de SHAPIRO-WILK (Proc Univariate), foram comparadas variâncias pelo teste $\mathrm{F}$ a $5 \%(\mathrm{P}<0,05)$ de significância.

\section{Resultados e Discussão}

O feno de alfafa em cubos acrescido de óleo de soja promoveu a maior média de digestibilidade da matéria seca (66,18\%) (Tabela 4), seguido pelo feno de alfafa em fardo com adição de óleo de soja (65,18\%), pelo feno em cubo $(60,60 \%)$ e pelo feno em fardo sem óleo rama $(60,10 \%)$.

A adição de óleo influenciou significativamente a digestibilidade da matéria seca ( $\mathrm{P}<0,01)$, o que confirma o observado por Hintz (1999), que, testando dietas para eqüinos contendo 20 a $25 \%$ de gordura na matéria seca, observou digestão de 70 a $90 \%$.

O processamento da alfafa (feno em cubo ou rama), no entanto, não influenciou $(\mathrm{P}>0,05)$ a digestibilidade da matéria seca $(\mathrm{P}>0,05)$. Não houve interação entre a adição de óleo e o processamento da alfafa $(\mathrm{P}>0,05)$.

$O$ feno de alfafa em cubos com adição de óleo foi o que apresentou o maior a maior digestibilidade (70,66\%), seguido pelo feno de alfafa em fardo com adição de óleo (69,82\%), pelo feno de alfafa na forma de cubos sem adição de óleo (66,46\%) e pelo feno de alfafa em ramas sem adição de óleo (65,34\%). Como a matéria orgânica é obtida pela diferença entre matéria seca e matéria mineral, possivelmente, a adição de óleo "top dress" contribuiu para o aumento da digestibilidade da matéria orgânica $(\mathrm{P}<0,05)$.

Por outro lado, o processamento do feno de alfafa (cubo ou rama) não influenciou a digestibilidade da matéria orgânica de alfafa (cubo ou rama) $(\mathrm{P}>0,05)$.

$\mathrm{O}$ feno de alfafa na forma de cubos foi o que apresentou maior digestibilidade da proteína bruta $(80,01 \%)$, seguido pelo feno de alfafa em cubos com adição de óleo (79,98\%), pelo feno em fardo $(76,70 \%)$ e pelo feno em fardo com adição de óleo (76,28\%). A digestibilidade da PB foi influenciada pelo processamento $(\mathrm{P}<0,05)$ da alfafa. Resultados semelhantes foram observados por Lambert \& Janique (s/d), que relataram que, apesar de as folhas constituírem menos de $50 \%$ do feno de alfafa, esta fração contém $70 \%$ da proteína e $90 \%$ do caroteno. Deste modo,

Tabela 4 - Digestibilidade dos nutrientes da dieta

\begin{tabular}{lcccccccc}
\hline Nutriente & Cubo & Cubo/Óleo & Rama & Rama/Óleo & Desvio-padrão & Valor P & Valor P Óleo & Interação tratamentos \\
\hline MS & 60,60 & 66,18 & 60,10 & 65,18 & 4,50 & NS & 0,0093 & NS \\
MO & 66,47 & 70,66 & 65,35 & 69,83 & 3,85 & NS & 0,0111 & NS \\
PB & 80,02 & 79,98 & 76,71 & 76,29 & 2,37 & 0,0048 & NS & NS \\
EE & 67,41 & 89,23 & 68,68 & 90,52 & 2,97 & NS & $<0,0001$ & NS \\
FDN & 42,15 & 47,15 & 47,92 & 53,24 & 7,39 & 0,0147 & 0,0257 & NS \\
FDA & 35,60 & 41,43 & 43,40 & 47,23 & 8,78 & 0,0237 & NS & NS
\end{tabular}

NS - Não-significativo.

MS - matéria seca; MO - matéria orgânica; PB - proteína bruta; EE - extrato etéreo; FDN - fibra em detergente neutro; FDA - fibra em detergente ácido. 
a relação folha/haste do feno, pode ter influenciado a digestibilidade aparente da proteína bruta, que foi maior $(\mathrm{P}<0,05)$ para o feno de alfafa em cubos em comparação ao feno de alfafa em fardos.

A adição de óleo “top dress” não influenciou ( $\mathrm{P}>0,05)$ a digestibilidade da PB. Também não houve interação $(\mathrm{P}>0,05)$ processamento de alfafa $\times$ adição de óleo de soja. Esses resultados são semelhantes aos obtidos por Cunha (1991) e Todd et al. (1995), que relataram que dietas com óleo não afetam a digestibilidade da PB em eqüinos. Jansen et al. (2000) também não encontraram diferença na digestibilidade da PB quando aumentaram a concentração de óleo na alimentação de eqüinos.

O feno de alfafa em fardos com adição de óleo ocasionou a maior digestibilidade do extrato etéreo (90,51\%), seguido pelo feno em cubo com adição de óleo $(89,23 \%)$, pelo feno em fardo $(68,68 \%)$ e pelo feno em cubo sem adição de óleo (67,40\%). A digestibilidade do EE foi influenciada $(\mathrm{P}<0,01)$ pela adição de óleo.

Bowman et al. (1977) observaram que a adição de óleo vegetal na dieta dos eqüinos aumentou a digestibilidade dos ácidos graxos. Kane et al. (1979), Julen et al. (1995), Todd et al. (1995) e Rammerstorfer et al. (1998) observaram aumento da digestibilidade do extrato etéreo e no balanço energético com o aumento do nível de lipídeos na dieta.

Os resultados obtidos neste trabalho com as dietas com adição de óleo vegetal podem ser justificados pela alta digestibilidade do óleo de soja, pois, de acordo com Meyer (1995), fontes lipídicas de alta digestibilidade, como os óleos vegetais, podem ser totalmente degradadas no intestino delgado. Swenson (1977) e Cunha (1991) afirmaram que a ausência de vesícula biliar nos eqüinos melhora a digestão e absorção dos lipídeos no intestino delgado, pois a bile é constantemente lançada nessa porção do sistema digestivo.

O processamento da alfafa (feno em cubos ou fardos), isoladamente ou em associação ao óleo de soja, não influenciou a digestibilidade do extrato etéreo $(\mathrm{P}>0,05)$, o que comprova ausência de interação $(\mathrm{P}>0,05)$ desses fatores.

$O$ feno de alfafa em fardos com adição de óleo foi o que apresentou maior $(\mathrm{P}<0,05)$ digestibilidade da fibra em detergente neutro (53,23\%), seguido pelo feno em fardo com adição de óleo (47,92\%) e pelos fenos em cubo com adição de óleo $(47,15 \%)$ e sem adição de óleo $(42,15 \%)$. Desse modo, a digestibilidade da fibra em detergente neutro foi influenciada pela adição de óleo $(\mathrm{P}<0,05)$ e pelo processamento do feno de alfafa.

A adição de óleo possivelmente modifica a cinética da passagem, diminuindo a velocidade de trânsito da digesta. Com o aumento do tempo de permanência, a exposição aos processos enzimáticos digestivos aumentou, colaborando para a melhoria na digestibilidade. A alfafa em fardo possui aproximadamente 15\% mais hemicelulose (FDN\%-FDA\%) e, como a digestibilidade da hemicelulose em eqüinos é maior que a da celulose (Pagan, 1998), isso pode ter influenciado a digestibilidade da FDN do feno de alfafa em fardo. O tipo de incrustação e a complexidade da lignina no feno de alfafa parecem ser menos severos, o que confirma a afirmação de Hartley \& Haverkamp (1984) de que, apesar dos altos teores de lignina, as leguminosas apresentam razoável digestibilidade da fibra.

Por outro lado, segundo Frape (1986), a gordura em excesso que não foi aproveitada no intestino delgado pode chegar ao ceco e cólon e assim inibir a fermentação bacteriana de componentes de fibra. No mesmo sentido, outros autores obtiveram resultados diferentes quando adicionaram uma fonte extra de gordura à dieta de eqüinos e não observaram alterações na digestibilidade da FDN (Kane et al.,1979; Davison et al., 1987; McCann et al., 1987; Meyers et al., 1987).

O feno de alfafa em fardos com adição de óleo foi o que apresentou maior $(\mathrm{P}<0,05)$ digestibilidade da FDA $(47,22 \%)$, seguido pelo feno em fardo sem adição de óleo (43,40\%), pelo feno em cubos com adição de óleo (41,42\%) e pelo feno em cubos sem adição de óleo (35,60\%).

Neste estudo a adição de óleo não influenciou $(\mathrm{P}>0,05)$ a digestibilidade da FDA, semelhante aos resultados obtidos por Kane et al. (1979), McCann et al. (1987), Julen et al. (1995) e Rammerstorfer et al. (1998), que não verificaram alterações na digestibilidade da fibra em detergente ácido relacionadas à adição de óleo em dietas para eqüinos.

\section{Conclusões}

A adição de óleo de soja refinado em dietas com feno de alfa em cubos ou em fardos e concentrado comercial aumenta a digestibilidade total da matéria seca, matéria orgânica, do extrato etéreo e da fibra em detergente neutro. O processo de fenação da alfafa na forma de cubos, em dietas para equinos, aumenta a digestibilidade total da proteína bruta, da fibra em detergente neutro e da fibra em detergente ácido.

\section{Literatura Citada}

ARAÚJO, K.V.; LIMA, J.A.F.; FIALHO, E.T. et al. Avaliação de períodos de coleta total de fezes para determinar a digestibilidade aparente dos nutrientes em eqüinos. Ciência Agrotécnica, v.27, n.4, p.886-893, 2003.

BOWMAN, V.A.; FONTENOT, J.P.; WEBB JR., K.E. In: EQUINE NUTRITION AND PHYSIOLOGY SYMPOSIUM, 5., St. Louis, 
1977. Anais... Equine Nutrition and Physiology Society, 1977. p.458.

BUSH, J.A.; FREEMAN, D.E.; KLINE, K.H. et al. Dietary fat supplementation effects on in vitro nutrient disappearance and in vivo nutrient intake and total tract digestibility by horses. Journal of Animal Science, v.7, p.232-239, 2001.

COLEMAn, R.J. [s.d.] Alfalfa cubes: an alternative forage. Department of Animal Science, University of Kentucky. Disponível em <http://www.neosoft.com/ iaep/pages/protected/ jissues/j1906/j1906p392.html> Acesso em: 25/06/2004.

CROZIER, J.A.; ALLEN, V.G.; JACK, N.E. et al. Digestibility, apparent mineral absorption, and voluntary intake by horses fed alfalfa, tall fescue, and caucasian bluestem. Journal of Animal Science, v.75, p.1651-1658, 1997.

CUNHA, T.J. Horse feeding and nutrition. 2.ed. San Diego: Academic Press, 1991. 445p.

DAVISON, K.E.; POTTER, G.D.; GREENE, L.W. et al. Lactation and reproductive performance of mares fed added dietary fat during late gestation. In: EQUINE NUTRITION PHYSIOLOGY SOCIET, 10., 1987, St. Louis. Anais... St. Louis: Equine Nutrition Physiology Society, 1987. p.87-92.

FRAPE, D. Ingredients of horse feeding. In: FRAPE, D. (Ed.) Equine nutrition and feeding. Essex: Longman Scientific and Technical, 1986. 373p.

HARTLEY, R.D.; HAVERKAMP, J. Pyrolisis - mass spectrometry of the phenolic constituents of plant cell walls. Journal of Science Food Agriculture, v.35, n.1, p.14-20, 1984.

HINTZ, H.F. Nutrition reports from ICEEP-5. Equine Practice, v.21, n.1, p.6-21, 1999.

HUGHES, S.J.; POTTER, G.D.; GREENE, L.W. et al. Adaptation of thoroughbred horses in training to a fat supplement diet. Equine Veterinary Journal, v.18, p.349-352, 1995.

JACKSON, S.G.; PAGAN, J.D. Growth management of young horses. A key to future success. Journal of Equine Veterinary Science, v.13, p.10-11, 1993.

JANSEN, W.L.; KUILEN, J.V; GEELEN, S.N.J. et al. The effect of replacing nonstructural carbohydrates with soybean oil on the digestibility of fiber in trotting horses. Equine Veterinary Journal, v.32, n.1, p.27-30, 2000.

JULEN, T.R.; POTTER, G.D.; GREENE, L.W. et al. Adaptation to a fat-supplemented diet by cutting horses. Proceedings Equine Nutrition Physiology Society, v.14, p.56-61,1995.

KANE, E.; BAKER, J.P.; BULL, L.S. Utilization of a corn oil supplemented diet by pony. Journal Animal Science, v.48, p.1379-1384, 1979.

LAMBERT, W.V.; JANIKE, E.W. Making hay with forced air. University of Nebraska - College of Agricultural and U.S. Department of Agriculture, s/d. 16p. (Extension Service).

McCANN, J.S.; MEACHAM, T.N.; FONTENOT, J.P. Energy utilization and blood traits of ponies fed fat-supplemented diets. Journal of Animal Science, v.65, p.1019-1026, 1987.

MEYER, H.S. Alimentação de cavalos. 2.ed. São Paulo: Varela, 1995. 303p.
MEYERS, M.C.; POTTER, G.D.; GREENE, L.W. et al. Physiological and metabolic response of exercising horses to added dietary fat. Proceedings Equine Nutrition and Physiology Society, v.10, p.107-113, 1987.

MOORE-COLYER, M.J.S.; LONGLAND, A.C.; HYSLOP, J. et al. Intra-caecal fermentation parameters in ponies fed botanicallydiverse fibre feeds. Animal Feed Science and Technology, v.84, p.183-197, 2000.

NATIONAL RESEARCH COUNCIL - NRC. Nutrient and Requirements of horses. 5.ed.rev. Washington, D.C.: National Academy Press, 1989. 100p.

OTT, E.A. Feeding the growing foal for optimum growth and development. In: ANNUAL CONFERENCE ON LIVESTOCK AND POULTRY IN LATIN AMÉRICA, 11., 1977, Gainesville. Proceedings... Gainesville: University of Florida Press, 1977. p.1-12.

PAGAN, J. Forages for horses: more than just a filler. In: PAGAN, J. (Ed.) Advances in equine nutrition. Nottingham: Nottingham University Press, 1998. p.13-27.

RAMMERSTORFER, C.; POTTER, G.D.; CUDD, T.A. Physiological responses of mature quarter horses to reining training when fed conventional and fat-supplemented diets. Journal of Equine Veterinary Science, v.18, p.175-183, 1998.

RICH, V.A.B.; FONTENOT, J.P.; MEACHAM, T.M. Digestibility of animal, vegetable, and blended fats of equine. In: EQUINE NUTRITION AND PHYSIOLOGY SYMPOSIUM, 7., 1981, Warrenton. Proceedings... Warrenton: Arlie House, 1981. p.30.

STATISTICS ANALYSIS SYSTEM - SAS. User's guide: Version 5, 1985. (CD-ROM).

SCOTT, B.D.; POTTER, G.D.; EVANS, J.W. et al. Growth and feed utilization by yearling horses fed added dietary fat. Proceedings Equine Nutrition Physiology Society, v.10, p.101-105, 1987.

SILVA, D.J. Análise de alimentos (métodos químicos e biológicos) Viçosa, MG: Universidade Federal de Viçosa, 1990. 165p.

STANIAR, W.B.; KRONFELD, D.S.; WILSON, J.A. et al. Growth of thoroughbreds fed a low-protein supplement fortified with lysine and threonine. Journal of Animal Science, v.79, p.2143-2151, 2001.

SWENSON, M.J. Dukes physiology of domestic animals. 9.ed. London: Cornell University, 1977. 914p.

TODD, L.K.; SAUER, W.C.; CHRISTOPHERSON, R.J. The effect of level of feed intake on nutrient and energy digestibilities and rate of feed passage in horses. Journal of Animal Physiology and Nutrition, v.73, p.140-148, 1995.

Van SOEST, P.J. Nutritional ecology of the ruminants. Corvallis: O. B. Books, 1982. 374p.

WEBB, S.P.; POTTER, G.D.; EVANS, J.W. Physiology and metabolic response of race and cutting horses to added dietary fat. Proceedings of Equine Nutrition Physiology Society, v.10, p.115-120, 1987.

WOLTER, R. Alimentatión del caballo. Zaragoza: Acribia, 1997. 172p. 